\title{
Environmental assessment of road construction materials and technologies with the use of production wastes
}

\author{
N. G. Mitrofanov ${ }^{1, *}, A$. Yu. Sushilova \\ FSBEIHE, Tyumen Industrial University 625001, Tyumen, Russia
}

\begin{abstract}
The following paper presents some results of long-term research on the urgent problem of recycling waste products and their use in road construction. The studied new materials and technologies are justified by the developments of Tyumen Industrial University. The aim of this work is to prove the technique, checking the ecological safety of the road materials with the use of waste products. Research techniques and test subjects are quantitative chemical analysis and biological testing of road material samples with waste additives obtained during drilling and oil production. Along with the standard procedures for analyzing the contamination and toxicity of water extracts, the authors have proposed and tested the evaluation of repeated and long-term extractions, imitating the possible environmental impact of waste products. The obtained results showed the environmental safety of the roadbuilding materials based on wastes.
\end{abstract}

\section{Introduction}

In the Tyumen region of the Russian Federation, having the most developed production and industry, the urgent problem is concerned with the processing and disposal of such large-capacity wastes as drilling waste - drilling cuttings (BC), oil production wastes, transportation and oil processing - oil sludge (OS). The road construction engineering is a promising area for the recycling and use of wastes in construction materials and structures. Quite extensive research and implementation works are conducted in this direction [1-7], including the developments of the Automobile Roads and Aerodromes Department of Tyumen Industrial University [8-10]. A number of new road-building materials using waste, experimental design and technological solutions have been developed, patented and put into practice [11-13]. As a rule, the studied waste belongs to hazard class IV, i.e. they are low-hazard, but nevertheless toxic wastes, which requires mandatory testing of environmental (ecological) and human (sanitary) impact during their disposal, together with an assessment of the physical, mechanical, structural properties of the resulting materials.

\footnotetext{
* Corresponding author: $\underline{\text { mng-tgasu@yandex.ru }}$
} 


\section{Materials and Methods}

Developments of the department have proposed and justified more than 10 new road materials and technologies using waste (BC, OS). A common feature of these wastes produced in various industries is their multiphase composition of many components (water, solid phase, organic and inorganic compounds, surfactants, petroleum products.

Road-building materials produced with the use of all of the enumerated wastes can be divided into groups: 1- strong cured binder compositions for construction of road pavements and other elements; 2- fertile mixtures using organics and sorbents for land restoration and slope enforcement; 3-soil mixtures for construction of embankments, elimination of sludge storage pits; 4- special materials for waterproofing, thermal insulation, and others. Our research and implementation works have tested standard methods of sanitary and ecological assessment of materials and technologies using wastes and also proposed a number of improvements, the algorithm and general research procedure are presented below.

1. It has been carried out the assessment of toxicity (by biological testing of water extracts and assessment of content (elements) in the waste itself and water extract - i.e. determination of free and bound forms of toxicants by methods of quantitative chemical analysis (QCA) - chlorides, sulfates, heavy metals, oil products, surfactants, etc., the hazard class of the waste has been specified.

2. Biological testing of the water extract from the construction material based on the recycled (cured, decontaminated) waste is carried out and the content of pollutants in it is evaluated. Practically in all cases, the tested building material, where waste components are structurally bound or absorbed in the composition, shows a significant reduction in leaching in the water extract, which indicates its environmental and sanitary safety. Repeated testing of materials toxicity on rodents also showed minimal hazard class. Vegetation experiments on the effect of recultivating mixtures containing wastes on wheat and oat seedlings showed low phytotoxicity of the materials.

3. A necessary requirement for experimental application of road materials, structures and technology is to organize environmental monitoring in the work area, including the preparation and approval of the project, selection and testing for pollution of natural environments (soil, groundwater and surface water) at the experimental site at a distance of $5-25-50 \mathrm{~m}$ (for example) from the foot of the embankment and at the control sites (without wastes).

4.Finally, the most important of our contaminants tested proposals, has not yet been reflected in the standard procedures. The study of the environmental impact of roadbuilding materials, along with the typical methods of biological testing and QCA, should simulate the process that will take place during the operation of the real structural components. That is to reflect two possible phenomena: 1 - the dynamics of the pollution density and toxicity level (by QCA and biological testing) of the standard primary - per 1 day, and repeated water extracts from the material with wastes (for example, after 2-3, 4-5, 6-7 days); 2 - the dynamics of pollution and toxicity of water extracts of different degrees of exposure, that is curing of the material with wastes ( 1 day - standard, and, for example, $7,15,21$ days).

The proposed test procedure reflects processes that may occur in practice, that is, it simulates, for example, repeated washouts of toxicants possibly released during rainfall, or increased environmental pollution during prolonged waterlogging of the waste-based road material structure.

In our studies we tested methods of evaluation of repeated and prolonged aqueous extractions from compositions based on BC and OS. Cured materials were crushed, sieved through a $5 \mathrm{~mm}$ sieve, then aqueous extracts were prepared: A - primary, secondary, third; 
B - with exposure of 1 day, 7 days, 21 days, extracts were studied for component content and toxicity.

\section{Results and discussion}

Repeated laboratory experiments have shown that the content of toxicants practically has not been increased significantly with increasing curing time from 1 to 21 days, and has been decreased many times with repeated extractions from one portion of the crushed material. This technique adequately simulates the possible, but not significant ecological impact of the structural element of the road using waste materials.

As an example, here are the data on the study of composite reinforced soil using oil sludge and water extracts from it. In order to study the possibility of migration of toxicants from the obtained material with water into the environment in more depth, we carried out the experiment on obtaining aqueous extracts: the crushed sample of the material was kept in distilled water in the ratio 1:10 for 24 hours, after that the water was drained for analysis (primary extract), the sample was divided in half and the first part was repeatedly filled with water for 24 hours (secondary extract), the second part was filled with pure water and kept for 7 days. Results of researches are presented in table 1,2.

In particular, samples of reinforced soil were prepared and tested using oil sludge, containing $6 \%$ of the viscous oil in the sludge and $8 \%$ of the cement per $100 \%$ of the soil.

Table 1. Test results of reinforced soil

\begin{tabular}{|c|c|}
\hline Name of the indicators & Meaning \\
\hline Density of mixes after molding. g/cm ${ }^{3}$ & 1.89 \\
\hline $\begin{array}{c}\text { Compressive strength of water-saturated samples at the age 28th } \\
\text { day. MPa }\end{array}$ & 4.4 \\
\hline Water absorption by weight. \% & 2.34 \\
\hline Water resistance coefficient & 0.89 \\
\hline Tensile strength (by splitting). MPa & 1.48 \\
\hline
\end{tabular}

Table 2. Content of toxicants in aqueous extracts of reinforced soil, mg/dm3.

\begin{tabular}{|c|c|c|c|c|c|}
\hline Component & $\begin{array}{c}\text { Content in the } \\
\text { material }\end{array}$ & $\begin{array}{c}\text { Primary } \\
\text { extract }\end{array}$ & $\begin{array}{c}\text { Secondary } \\
\text { extract }\end{array}$ & $\begin{array}{c}\text { Secondary } \\
\text { extract } \\
7 \text { days }\end{array}$ & $\begin{array}{c}\text { Maximum allowable } \\
\text { concentra-tion in } \\
\text { domestic water }\end{array}$ \\
\hline $\begin{array}{c}\text { Petroleum } \\
\text { products }\end{array}$ & $1035 \pm 466$ & $0.09 \pm 0.04$ & $0.05 \pm 0.02$ & $0.06 \pm 0.02$ & 0.3 \\
\hline Sodium & $747 \pm 56$ & $24.3 \pm 2.4$ & $3.1 \pm 0.3$ & $3.4 \pm 0.3$ & 200 \\
\hline Iron & $<1$ & $<0.05$ & $<0.05$ & $<0.05$ & 0.3 \\
\hline Potassium & $334 \pm 33$ & $12.0 \pm 1.2$ & $4.9 \pm 0.5$ & $5.6 \pm 0.6$ & - \\
\hline Lead & $<0.5$ & $<0.001$ & $<0.001$ & $<0.001$ & 0.01 \\
\hline Chloride ion & $102 \pm 20$ & $3.2 \pm 0.5$ & $0.65 \pm 0.1$ & $1.3 \pm 0.2$ & 350 \\
\hline Sulfate ion & $941 \pm 188$ & $47.8 \pm 7.2$ & $13 \pm 2$ & $12.6 \pm 1.9$ & 500 \\
\hline
\end{tabular}


Only microquantities of toxic compounds washed out mainly from the surface of the material granules (primary extraction) were transferred into the aqueous extract from the reinforced soil. Even in the primary extraction and 7-day extraction, the content of toxicants is many times lower than the maximum allowable concentration; in most cases, the amount of leached compounds is greatly reduced in repeated samples and does not pose a threat to the environment. In this example, as in many other experiments performed, it has been shown that the contamination of the extracts practically has not been increased with increasing curing time, and has been decreased with repeated extractions.

Scientific originality of the following paper is in the justification and experimental proving of the presented technique - the ecological assessment of road materials using waste, adequately simulating the practical situation.

\section{Conclusions}

Experimental results show that from the surface of road-building material based on waste it is possible insignificant primary "washout" of pollutants into the environment, while their concentration does not exceed the background one, and in subsequent rains and waterlogging pollution will not be increased.

For a rapid environmental assessment, it is sufficient an additional study of one repeated aqueous extraction increased up to 7 days.

The data of ecological monitoring also confirm the statement about the absence of environmental pollution when using hardened road composite materials with the use of production wastes if the construction technology is observed.

\section{References}

1. K. O. Maloney, Cambridge University Press, 14 (4), 278-287 (2012)

2. M. Abukhettala, Proceedings of the 2nd International Conference on Civil, Structural and Transportation Engineering (ICCSTE'16), 138 (2016)

3. A. Tuncan, Waste Management \& Research: The J. for a Sust. Circular Economy. 18(5), 489-505 (2000)

4. I. Isaeva, Bulletin of the Moscow State Automobile and Road Technical University (MARI), 3(42), 114-119, (2015)

5. E.A.A. Pichugin, Young Scientist, 9(56), 124-126, (2013)

6. B.S. Yushkov, Env. protection in the oil and gas sector, 6, 41-44. (2010)

7. L.P. Kapelkina, N.E. Orlova, T.V. Bardina, L.G. Bakina, N.V. Rusakov, E.Y. Kruchinina, N.G. Mitrofanov, Industrial Ecology - 97: reports of scientific and practical conference, 213-217 (1997)

8. N. G. Mitrofanov, Construction of highways using composite materials based on soils and drilling waste (by example of oil producing areas of Western Siberia): Ph. ... Cand. of Technical Sciences (SPb, 2000).

9. D. M. Karimov, New technologies - oil and gas region: Proceedings of the international scientific-practical conference of students, graduate students and young scientists, 248-251 (TIU, Tyumen, 2017)

10. M. S. Boyko, New technologies - oil and gas region: materials of the annual AllRussian creative competition of research and design works, 78-81 (TIU, Tyumen 2018) 
11. I.N .Koltsov, N.G. Mitrofanov, V.S. Petukhova, L.N. Skipin, Patent № 2491135 Russian Federation, IPC B09B 1/00 (2006.01). Soil slurry-soil mixture (variants) for recultivation of disturbed lands and the method of recultivation of pits and disturbed lands, Bulletin №24. (2013).

12. N. G. Mitrofanov, M. V. Kudomanov, I. V. Panov, D. A. Rumyantseva, Patent №. 2520593 Russian Federation, IPC C04B 14/12 (2006.01), C04B 33/13 (2006.01), C04B 38/06 (2006.01) Raw mix for the production of expanded clay, Bulletin №18 (2006)

13. N.G. Mitrofanov, I. N. Zenkin, Patent number 2471737, Russian Federation, MPK C04B 28/00 (2006.01). Composite building material, Bulletin №1 (2013) 